\title{
Study on the Feasibility of Setting up Archery in Shaanxi Xueqian Normal University
}

\author{
$\mathrm{Li} \mathrm{Li}$ \\ Department of Physical Education \\ Shaanxi Xueqian Normal University \\ Shaanxi, China
}

\begin{abstract}
This article uses the literature review method and the survey and interview method. The author analyzes the feasibility of setting up the course of traditional Chinese archery in colleges and universities. Finally, it has made the conclusion. And in his opinion, "archery" can effectively promote the harmonious development of college students' body and mind. In the university, the archery field, equipment, teachers, safety and other things can meet the relevant requirements. Therefore, it can also build a reasonable, scientific and diversified evaluation system of archery course. This is not only the rejuvenation of traditional competitive sports, but also the inheritance of the historical humanistic spirit.
\end{abstract}

Keywords-colleges and universities; archery course; Shaanxi Xueqian normal university

\section{INTRODUCTION}

With several thousand years of historical precipitation and development, traditional Chinese archery has gradually jumped out of the circle of pure competitive sports. And it has evolved into a diversified cultural complex. In addition to having the attributes of competitive sports, it also shows the return of humanities and culture. Chinese traditional archery also has a variety of cultural attributes and functions such as industry, politics, soldiers, learning, courtesy, and literature.

Since the 18th CPC National Congress, we have proposed the development of "powerful cultural country". And Chinese traditional culture has drawn more and more attention from the community. Some traditional Chinese cultural heritage on the brink of lost territory has been discovered, protected and popularized. As one of the six ancient cultural heritages, "archery" is in this atmosphere. China's archery is on the edge of extinction. And in many places, the form of etiquette is unclear or controversial. It needs to be combined with traditional cultural theories on the theory of restoration in China. Literally, "archery" should be the art of archery. However, it is not only a sport, and it is also the cultivation. With the technical practice and the understanding of traditional culture, it has cultivated good moral training in training programs. And it can be called as a science.

\section{RESEARCH METHODS}

China is one of the earliest countries in the world to invent bow and arrow. In the long course of history, there are 120 works related to "shooting art". These historical sites are rich in content. The historical values and cultural values are extremely high. And they are precious national and cultural heritage. Since ancient times, shooting art focuses on the combination of self-cultivation and inner perception. The socalled "Qing Qiantang" and "Li Qiguan" are the fusion of the "hearts". The famous ideologist and founder Li Yanxue has the works of "Book of Rites", "Justice", "Record", "The road of love" and so on. If it is right, it would be developed. If it can't win, we have to find out the reason. To learn archery is also to practice heart. It means that we should relax the body by adjusting and controlling the breathing rhythm. And then, we could calm the mind. Then, it would bring the body and mind into a good state. $\mathrm{Xu}$ Cai, who published "Nine Disciplines of Archery" at the forum, also summarized the characteristics of the refined language of moral practice. In "The Bible", the archery wouldn't make us happy. And the happiness makes the heart easy to fall. If we do not shoot, we wouldn't worry anything. And the trouble would make us be confused. And then, there is no trouble. We should hold the bow, arrow, look at the target and so on.

The author looks up into the CNKI, and there are about 19 articles on "archery". Mr. Ma Mingda published an important essay — "Chinese ancient archery". Ma Lianzheng has made the review on the researches on archery in China. Personally, I think that Chinese shooting science and ancient Chinese shooting books are the most important achievements of modern Chinese shooting research. To a certain extent, it shows that the research on archery has entered a new stage in China. However, there is no article combining shooting techniques with college sports.

\section{RESULTS AND ANALYSIS}

\section{A. To Promote the Harmonious Development of Physical and Mental Health with "Archery" Effectively}

Archery emphasizes that we should correct attitude. And it also focuses on the linear health of human physiology and archery symmetry. The archery is non-confrontational sports. When we have the archery, it is always hard and soft 
Therefore, we should always take a deep breath and smooth. And we can see the biggest advantage. The archery should have regular movements. It can experience the advantages and disadvantages of the correct posture. It could increase lung capacity, muscle strength, and can improve virtue and cultivate body and mind. God said that we should not shoot for different families. Therefore, the posture of archery is so elegant and polite. However, the essence of modern sports is impertinence and fickleness. And it can't be mentioned in the same breath. The ancients used to pursue the nature. A peaceful and calm attitude should be healthy and long-term. And then, the learning path would be smooth and full. In practice, there are rules. And rules are the only way to get real freedom. The archery movement requires us to master the skills of controlling muscle actions. And then, we may overcome their own instinct impatience, relaxation, atrophy, hesitation, slackness, complacency and so on.

Archery sports have the functions of self-cultivation. The college students would comprehend life and promote the harmonious development of body and mind in simple archery movements. We should shoot the arrow on the target. And the shooting would be intensive. However, it does not make sense. And if we continue to defeat ourselves and make progress, it is the fun or meaning of archery. The shooter should correct the attitude. And then, if they do not shoot on the target, they can't complain about those who are better than themselves. And they would ask the reasons.

\section{B. To Better Understand Chinese Ancient Civilization through Practicing the "Archery"}

The traditional "Chinese archery" has a wide range of connotations including excellent traditional culture, traditional Chinese philosophy, etiquette, literature, martial arts, modern psychology and natural science. At the same time, in order to have archery and cultivate their knowledge, students should better understand the essence of Chinese archery in Chinese traditional archery. Everyone has difficulties and obstacles in archery. For example, we can't shake the arrow. It would cause restlessness and instability of limbs. If we always run the arrow, we would be discouraged. If the others are stronger than us, we would envy them. When we have the game, we would always worry about shooting. And then, we will be anxiety. These negative emotions affect the psychology. Thereby, it would affect the archery competition. In order to overcome the psychological barrier caused by negative emotions or overcome the weakness of human nature, we should take good care of body, calm down inner heart, admit the mentality, relax the mind, adjust the attitude, and breath smoothly. Then, we would create a good state for the archery competition. The students would study the Chinese ancient civilization in the books. Also, they can study archery through shooting art. And then, they would understand the culture during the study of archery, and experience the wisdom and thoughts of forerunners.

\section{Shaanxi Xueqian Normal University can Effectively Ensure the Archery Equipment and Safety Requirements of Teachers on Archery}

From the perspective of the speed or depth, it wouldn't be too fast or too slow. Most people can do collective exercise. Also, individuals can practice alone. The target can be at the spot for photography. And you can shoot in a small room. We can practice anytime and anywhere without space and time constraints. According to the conditions of Shaanxi Xueqian normal university, it can provide the archery venue. And even, the school can also invest in a new venue. Archery is easy to learn. Teachers can focus on the development of related teaching. Teachers of Shaanxi Xueqian normal university, especially the teachers of the department of physical education, have high cultural qualities. In teaching, they can teach the students' knowledge about "archery". Everyone is worried about the safety of archery. In our practice, a round-headed design has been developed that embodies both culture and technology. Also, it is complete understanding of ancient shooting techniques. Combined with the actual situation of Shaanxi Xueqian normal university, we can also use the quality evaluation results to complete the evaluation system.

\section{Shaanxi Xueqian Normal University can Create Reasonable, Scientific and Diversified Evaluation System of Archery Curriculum}

Shaanxi Xueqian normal university can design a related assessment system based on their own teaching situation. And it would be helpful to improve the archery teaching. Here, the author would give an example. Archery can be divided into shooting and archery in ancient times. In the teaching evaluation, we should consider shooting and archery. In the test field, a group includes four people $(0$ viewers, 1 people shooting, 2 shooters, and 3 arrow children). And they would be replaced in turn. When all of the four people show the shooting skills, the competition is over. And we can make the rating: top (middle, middle and bottom), middle (top, middle and bottom), bottom (top, middle and bottom), three-level, and nine-level. We can get fourcharacter score: $10 \%$ of the audience, $10 \%$ of arrow children, and $40 \%$ of shooting, $40 \%$ of shooter. This not only highlights the cultural connotation, but also considers the accurate technology. This evaluation design is the combination of culture and technology. And it is the comprehensive understanding of the ancient art of shooting. Combined with the actual situation of schools, it could use quality evaluation results to complete the evaluation system.

\section{CONCLUSION}

In the several thousand years of history in China, the development of bows and arrows has been accompanied by the progress of Chinese civilization. And it has had profound impact on many aspects of social life. In 1959, China started to compete in accordance with the international archery rules and accepted the texture and production methods of the international bow. And it was completely different from the Chinese bow. The Chinese shooting quietly left the stage. In recent years, with the rejuvenation of Chinese traditional 
culture, those who are interested in the bow and arrow culture actively interpret and promote it. They enrich the traditional sports theory of the nation, and inherit and carry forward the traditional culture. Under the background of "powerful cultural country", Chinese traditional culture has drawn more and more attention from the society. As the "archery" of the six ancient arts, many archery enthusiasts would dig and promote it.

For the feasibility of Chinese archery in physical education in colleges and universities, the author conducted an in-depth analysis. The author takes Shaanxi Xueqian normal university as the research object. The author finds that the practice of archery can effectively promote the health of college students. The students can better understand the ancient Chinese literature. At the same time, the university can effectively guarantee archery equipment and safety requirements. They also can establish scientific and rational and diversified evaluation system of archery curriculum. Therefore, it is not only the revival of traditional competitive sports, but also the excavation and orderly inheritance of the historical humanistic spirit. In other words, the university teachers of physical education should guide students to tap the historical and cultural tradition of Chinese shooting art. And its inheritance and development would be the cultural phenomenon with eternal value and significance.

\section{REFERENCES}

[1] Zhang Xu, Miao Hua, An Jiang. Chinese traditional "archery" and "Chinese ancient civilization" [J]. Journal of Northwest University, 2013 (1).

[2] Ma Mingda. Chinese ancient archery [J]. Jinan Historiography, 2013 (12).

[3] Qi Jiguang. Ji Xiao Xin Shu [M] Beijing: Zhonghua Book Company, 1996.

[4] Qian Feng. Study from practice to heart [J]. Chinese Heritage, 2013 (8).

[5] Guo Xiaobo. Tips of the criticism on traditional archery [J]. Chinese Culture Forum, 2011 (3).

[6] Ma Lianzhen. Summary of Chinese Archery Research [J]. Sports Culture Guide, 2004 (10).

[7] Li Mengkui. Cultural Implication of archery in Pre-Qin dynasty [J]. Journal of Beihua University, 2004 (6).

[8] Yuan Peng. Analysis on the feasibility of introducing archery into physical education in colleges and universities [J]. Physical Education, 2012 (9).

[9] Cui Zhifeng. Research on archery and its sports in Han dynasty [J]. Journal of Hunan Medical University, 2010 (7).

[10] Li Xinxiu, Chen Keyao. Comparison of sports between ancient Greece Olympic Games and China's Spring and Autumn and Warring States period [J]. Journal of Nanjing Institute of Physical Education, 2002. 